\title{
A urgência do debate: as contrarreformas na política da saúde no governo Temer
}

\author{
The urgent debate: counter-reforms in the health policy of the Temer government
}

\section{Mary Jane de Oliveira TEIXEIRA*}

\section{Introdução}

ndiscutivelmente, a configuração que o Brasil tem hoje do Sistema Único de Saúde (SUS)

$\mathrm{I}$ é fruto de muita luta, com momentos de dissensos e consensos, avanços e recuos, sobretudo pela força dos movimentos sociais, entre eles, o da Saúde, desde a Assembleia Nacional Constituinte (1987), período histórico que culmina com a promulgação da Constituição Federal de 1988 (CF/88).

A partir deste necessário recorte, iniciamos concordando com os autores (BRAVO; PELAEZ; PINHEIRO, 2018), quando estes explanam a presença forte de luta (luta de classe, acrescentamos), pela direção da política setorial, representada por dois projetos com interesses antagônicos, o que denominam didática e politicamente como Projeto da Reforma Sanitária e o Projeto Privatista (anos de 1970/80).

Concordamos que naquela dada conjuntura social e política, havia uma clara e acentuada disputa entre as forças progressistas na área da Saúde em especial - de cunho reformista e social-democrata - e as forças representadas pelo capital, no país. As forças progressistas apresentavam elementos de inovação: a participação social como produto da democracia que se almejava na sociedade brasileira. Surgia não só como elemento de resistência às marcas da repressão, opressão/coerção, de vozes silenciadas pela ditadura militar e como parte da luta pelo seu fim e também com propostas concretas para uma Política Nacional de Saúde votada para as reais necessidades da maioria da população brasileira: os trabalhadores.

Nesta direção, o Projeto de Saúde com base na Reforma Sanitária (PRS), combinava a luta específica com um projeto societário, onde a exploração do homem pelo homem e suas correntes opressoras seriam rompidas, superadas. Assim, o PRS, tal como posto pelos autores, reconhece a Saúde como um direito de todos os brasileiros, portanto, Universal. Para sua materialização, seria necessário que o Estado se fizesse presente e forte, como mediador de interesses opostos, na luta de classes.

\footnotetext{
*Assistente Social. Doutora em Serviço Social pela UERJ. Professora-Adjunta da Faculdade de Serviço Social da Universidade Estadual do Rio de Janeiro (UERJ). Rua São Francisco Xavier, 584, Maracanã, CEP. 20550900, Rio de Janeiro (RJ). E-mail: <mary-teixeira@uol.com.br>. ORC ID: <https://orcid.org oooo-ooo3$2815-408 x>$.
} 
As forças representativas do capital traziam o Projeto Privatista para a disputa, defendendo a saúde como uma mercadoria, posta no mercado para a venda. Na verdade, no período da ditadura militar que se expandiram os convênios governamentais (inicialmente federal, depois estaduais), com consultórios, clínicas, laboratórios, hospitais privados. Soma-se a expansão da compra, pelo Estado, de equipamentos e medicamentos do setor privado, entre outros. Como também, foi nesta quadra histórica, o surgimento dos planos e seguros privados de saúde. Apesar disso, este setor ainda não estava satisfeito, queriam a ampliação de seus domínios mercadológicos, com vistas à acumulação capitalista.

Como afirmam os autores, a atual defesa de interesses privados neste campo não é nova, ganhou “[...] robustez no período da ditadura militar" (BRAVO; PELAEZ; PINHEIRO, 2018, p. 9). Os defensores do Projeto privatista não têm como finalidade evitar o adoecimento dos sujeitos sociais, pois o que lhes permite a realização do lucro é a doença. Para eles, um nicho de mercado cada vez mais com potencial de crescimento, ainda que no Brasil, cujos indicadores de saúde são extremamente negativos.

A seguir, os autores se referem aos modelos de gestão diferenciados do SUS, surgidos pós anos de 1990, quando então o setor privado assume também a execução e gestão das ações de saúde. Isto é grave e preocupante, pois o Estado, não só se descaracteriza enquanto provedor da atenção, como previsto na $\mathrm{CF} / 88$, mas principalmente porque alarga o repasse do fundo público para o setor privado (TEIXEIRA, 2010a).

Esta nova formatação, privilegia a lógica da expansão e ocupação do capital, em aliança com o Estado. Aliança presente desde a origem do capitalismo, avançando no período do capitalismo monopolista e acentuando-se com aparente contradição na contemporaneidade de sua fase financeirizada. Andrade (2012) mostra-nos como Marx e Mèszaros explicavam esta relação e a real natureza de classe do Estado "[...] para Marx e Mèszaros, a existência do Estado está inseparavelmente ligada à reprodução econômica do sistema do capital, em outros termos, ela é o fundamento ontológico objetivo do próprio Estado moderno" (ANDRADE, 2012, p. 26).

Nesta direção, vemos que a natureza de classe do Estado se apresenta, quando Netto (2001), se refere que se vive na sociedade capitalista em tempos presentes, a existência de um Estado Mínimo para o trabalho e Máximo para o capital.

Desse modo, o setor Saúde, a partir dos anos de 1990, vive os efeitos prolongados da crise estrutural do capital, advinda dos anos de 1970 (mudança do padrão de acumulação, com a reestrutura produtiva, a precarização do trabalho e a flexibilização dos direitos para a classe trabalhadora, entre demais elementos), em âmbito internacional, com diferenças em cada país e seu nível de desenvolvimento das forças produtivas. Para seu alcance, o Estado também foi formatado, devendo retirar-se de suas funções de proteção social, fundamentado nas premissas da ideologia neoliberal.

No que diz respeito à relação entre o Estado e o capital, entendemos que para realizar-se enquanto tal, uma das ferramentas da qual se utiliza é o poder do Estado em regular o trabalho por meio dos poderes legislativo e judiciário. Neste sentido, o ideário neoliberal é o instrumento de suporte. Assim, concordamos com Allan (2016) afirmando que:

Argum., Vitória, v. 10, n. 1, p. 33-50, jan./abr. 2018. 
[...] os detentores dos meios de produção sempre perseguiram o ideário neoliberal de desregulamentação de direitos [...]. Neste cenário, a intervenção estatal é indesejada, pois, ao obrigar o cumprimento de determinados direitos à classe trabalhadora, o Estado impõe freios à exploração da mão de obra, constrangendo a acumulação capitalista (ALLAN, 2016, p. 332).

No Brasil, para alcançar os objetivos destas transformações societárias após os anos de 1990, é a partir do governo de Fernando Henrique Cardoso (1994-2002) (FHC), do Partido da Social-Democracia Brasileira (PSDB), que este ideário tem sua forma mais organizada, quando a contrarreforma do Estado se concretizará. Para tal, é implantado o Plano Diretor da Reforma do Estado (PDRE)/1995 e criado o órgão público que elaborará e implantará tal política: o Ministério da Administração e Reforma do Estado (MARE), em 1995 (TEIXEIRA, 2010b).

\section{A POLÍtTICA NACIONAL DE SAÚdE PÓS ANOS 2000: O GOVERNO DO PT GOVER- NOU PARA OS TRABALHADORES?}

Os autores convidam ao debate, quando se referem ao que denominam a possibilidade de um terceiro Projeto para a Saúde: o da Reforma Sanitária Flexibilizada, o do SUS possível. Como este terceiro projeto surge nos governos petistas, pensamos ser pertinente falarmos de forma breve como analisamos o que ocorreu com o Partido dos Trabalhadores (PT), ao (para) alçar o cargo máximo do país, a presidência da República, para então entendermos sua direção política, principalmente no que tange às políticas sociais, entre elas, a Saúde.

Consideramos que o partido, ao optar por priorizar mudanças societárias restritas ao âmbito institucional, pela ocupação nos espaços de poder, foi no mínimo um equívoco. A escolha por um projeto de poder em detrimento de um projeto que pensasse o país, trouxe alguns dividendos positivos momentâneos, pontuais, mas trouxe também problemas para o futuro. No segundo mandato (de Lula da Silva), a direção do PT alargou o leque de alianças, inclusive para partidos de centro e mesmo centro-direita, de perfil conservador. As consequências desta alternativa ideopolítica surgiram e de forma intensa, refletindo-se até a atualidade. São os compromissos que levam o PT e seus aliados, a optarem pela mesma linha macroeconômica de viés neoliberal (dos governos de Collor de Mello e FHC), incluindo submeter-se aos ditames das agências financeiras multilaterais, permanecendo a subalternidade do Estado brasileiro.

Neste sentido, podemos apreender porque uma Política Nacional de Saúde que aparece como avançada, que recupera os princípios do legislado (SUS/9o) e identificada com o Projeto de Reforma Sanitária, segue, na verdade, a lógica da economia política pré-estabelecida pelo capital, ainda que inegavelmente, algumas medidas no campo popular-democrático tenham sido tomadas. Pode-se afirmar que o PT passou a lidar com a mais forte contradição e dilema que um partido de esquerda conviveria: ao buscar uma (pretensa) conciliação entre as classes antagônicas, podia vir a se tornar um Comitê Executivo da burguesia (MARX; ENGELS, 2003), ou seja, como apontam os autores, "[...] cumprir o papel funcional ao capitalismo no Brasil” (BRAVO; PELAEZ; PINHEIRO, 2018, p. 10).

Por isso perguntamos se na verdade, não há somente, dois projetos, posto que, em nossa opinião, o Projeto da Reforma Flexibilizada se enquadraria no próprio projeto do capital. Foi no governo de Lula da Silva que o Ministério da Saúde encaminhou o Projeto de Lei 92/2007

Argum., Vitória, v. 10, n. 1, p. 33-50, jan./abr. 2018. 
de criação das Fundações Estatais de Direito Privado, não conseguindo aprovação por muita luta do movimento social em saúde (TEIXEIRA, 2010a). No entanto, no início do governo de Dilma Rousseff (2011-2016) foi aprovada a legislação da EBSERH (BRASIL, 2011). ${ }^{1}$ E antes de sua saída pelo afastamento, aprova a Lei 13.097 em 19 de janeiro de 2015 (BRASIL, 2015), cujo Artigo 142 permite a "[...] Abertura ao capital estrangeiro para oferta de serviços de saúde" (BRASIL, 2015, NÃO PAGINADO). Portanto, a meu ver, não há flexibilização quanto ao PRS e sim, sua abdicação.

Apesar de nos documentos governamentais petistas na área da Saúde, encontrarmos referência ao PRS e a necessidade de seu resgate, como apontam os autores, percebe-se que o SUS/9o não se materializa. As razões foram colocadas acima: a opção petista em seguir a economia macroestrutural do capitalismo em sua fase financeirizada.

Consideramos que o PT ao optar pela via parlamentar como forma de responder às demandas da classe trabalhadora e seu projeto democrático-popular esgotou-se no percurso de sua gestão (14 anos). Sua derrota não foi resultante apenas dos adversários políticos que a promoveram e sim, o processo de transformismo pelo qual passou (MARCONSIN, 2009; TEIXEIRA, 2010a). ${ }^{2}$

Na medida em que o "pacto3" é rompido, em que o Estado se distancia cada vez mais da sociedade civil, o PT ao adotá-la, se afasta da classe trabalhadora. Mas o partido ainda vivia o dilema entre o discurso e o gesto, em busca da coerência perdida nas entranhas do poder. A divisão interna ainda permitiu uma frágil resistência frente ao projeto burguês em sua totalidade. A partir de então, segundo Genro (2016) “[...] este é em um contexto em que o próprio partido de esquerda, mais importante da época, perdeu a sua capacidade dirigente e ‘queimou' seu período áureo [...]” (GENRO, 2016, p. 392).

A perspectiva do transformismo chegou aos diferentes espaços, nas políticas governamentais, entre elas, a da Saúde (PAIM, 2008). O PT abandonou as bandeiras emancipatórias da classe trabalhadora em detrimento da participação nos espaços políticos da burguesia. A luta por meio dos movimentos sociais foi secundarizada ${ }^{4}$. Diferentes movimentos sociais (inclusive o da reforma sanitária), também passaram por este processo de mudanças de posição e recuaram frente às suas formas de luta, sua combatividade, preferindo o projeto de conciliação de classes, tendendo a burocratizar-se. O recuo das lutas de rua e pressão frente às políticas de governo contribuíram com um gradativo processo de despolitização na sociedade

\footnotetext{
${ }^{1}$ Lei 12.550, de 15 de dezembro de 2011. Dispõe sobre a criação da Empresa Brasileira de Serviços Hospitalares (EBSERH) nos Hospitais Universitários (HUs) da Universidades Federais.

${ }^{2}$ Esta categoria social construída por Gramsci (1978) foi a ferramenta explicativa que encontramos para entender a direção política que o Partido dos Trabalhadores seguiu para a tomada do poder por meio de eleições. Em síntese, identifica-se o transformismo, quando uma classe social assume o projeto da outra classe. 3 Na Carta ao Povo Brasileiro Lula da Silva fala em "um novo contrato social" e "tranquiliza" o capital internacional quanto ao que será o seu governo.

4 Ao priorizar a via parlamentar como espaço de mudanças, o PT caiu em sua própria armadilha. Hoje, (março de 2018), sua mais representativa liderança e um dos fundadores, em aparente contradição, para não ir preso, depende de uma instituição que participou com força e convicção de sua derrocada. Isto porque o processo de despolitização que a sociedade brasileira viveu durante seus governos (a passivização) até os momentos atuais, além de abrir espaço para os conservadores, não conseguiu aglutinar força sociais progressistas e populares capazes de interromper o golpe e suas consequências nefastas.
}

Argum., Vitória, v. 10, n. 1, p. 33-50, jan./abr. 2018. 
brasileira, de passivização, ao ponto de chegarmos a um estágio de barbárie social, com frágil resistência5.

\section{O RETROCESSO COMO PERSONIFICAÇÃO: A SAÚDE NO GOVERNO TEMER}

Para fundamentar as críticas ao governo Temer, Bravo, Pelaez e Pinheiro (2018) adotam o procedimento metodológico baseado no estudo dos três (3) documentos oficiais, por considerá-los significativos e emblemáticos, onde está presente a intenção central do $\mathrm{PMDB}^{6}$ em aprofundar as privatizações em curso, atingindo de forma avassaladora, o setor Saúde. Temer ${ }^{7}$ ainda como presidente interino, a partir de meados de maio de 2016 , busca viabilizar a aprovação de legislações que estavam represadas pelas forças políticas em disputa.

O caminho para a privatização das políticas sociais e da Saúde em destaque vão se alargando, no entanto, é crucial apontar que "[...] os processos de privatização e de retrocessos na política de Saúde não começam no governo Temer” (BRAVO; PELAEZ; PINHEIRO, 2018, p. 11). O agravamento deste caminho é o fato de não ter sido interrompido durante os governos petistas, de cunho democrático-popular. Não houve mudança no curso da história da Saúde e o PRS, não se consolidou como política de Estado. O caráter público, universal e com participação social ${ }^{8}$ foi cada vez mais se distanciando do legislado.

O golpe (legislativo, midiático, jurídico) desnudou as fragilidades da democracia burguesa e abriu espaço para o debate frente às forças sociais de esquerda e populares, quanto à viabilidade da política de conciliação de classes em países periféricos ao capital, com acentuada desigualdade social e econômica (HARDOON; AYELE; NEIVA, 2016). Acrescendo a importância de pensar a singularidade do Brasil, com sua formação social fundada em bases escravocrata (SOUSA, 2017). Temer inegavelmente representa os setores mais reacionários, atrasados e conservadores da sociedade brasileira, aliado à burguesia "[...] ultra neoliberal, claramente pró-capital, que visa resolver os impasses de acumulação e favorecer os interesses da classe dominante no país e aprofundar sua dependência junto ao capital internacional" (BRAVO; PELAEZ; PINHEIRO, 2018, p. 12).

\footnotetext{
5 Na cidade do Rio de Janeiro em março de 2018 temos dois fatos que atingem a democracia: o assassinato de uma vereadora - militante representante da população moradora em favelas (pobre), de mulheres e negras e defensora dos Direitos Humanos. No município de Maricá, a morte por tiros de cinco jovens da periferia (professores de dança). Trabalho com uma ONG e prefeitura, no campo da cultura.

6 Em convenção nacional, de 19 de dezembro de 2017, este partido mudou o nome para Movimento Democrático Popular, voltando à sigla anterior: MDB, mas para efeito deste trabalho, considerando o artigo que ora está em debate, continuaremos a referirmos à sigla presente no texto dos autores.

7 A posse de Temer como Presidente da República do Brasil foi em 31 de agosto de 2016. A tarefa de Temer é responder aos anseios mais prementes do capital, como resposta à luta de classes que foi se acirrando no breve percurso histórico de 2013, acelerando-se após a vitória de Dilma Rousseff nas eleições de 2014. As principais tarefas são as contrarreformas: a Lei da Terceirização, a Trabalhista e da Previdência Social, que estavam sendo dificultadas sua aprovação na gestão Dilma. Estas propostas foram retomadas pelo PMDB, em documento como os aqui estudados: a Agenda Brasil e o Uma ponte para o futuro. A tarefa não cumprida (durante todas as tentativas em 2017 e início de 2018), pela correlação de forças na sociedade civil e sociedade política, foi aprovar a contrarreforma da Previdência Social.

8 Por exemplo, o Pacto de Gestão, de 2006, do Ministério da Saúde, que dispõe sobre a descentralização da gestão em Saúde, não define o Conselhos de Saúde com caráter deliberativo, apesar de assim estar previsto na legislação do SUS: Lei 8.142/1990.
}

Argum., Vitória, v. 10, n. 1, p. 33-50, jan./abr. 2018. 
Acrescentamos apenas que na verdade, continuamos com o neo(colonialismo), (FERNANDES, 1986) pois a época da exportação de matéria-prima foi ultrapassada enquanto discurso e agora temos a substituição/sofisticação para o inglês, as commodities (acentua a colonização) revelando a subalternidade, elemento historicamente estrutural, hoje com predominância do capitalismo financeirizado que dá a direção à vida pública, por meio de seus representantes nacionais.

Para Antunes (2016) ${ }^{9}$ este é um governo terceirizado, representante dos interesses internacionais, sem projeto para o país, contratado para atender os patrões: o império. Para materializar este projeto ultraneoliberal entre 2015-2016, os três documentos apresentados pelo PMDB são emblemáticos, visto que apontam a "[...] aceleração e intensificação de medidas que contribuem com o desmonte do Estado brasileiro, configurando uma nova fase de contrarreformas estruturais que atacam os direitos dos trabalhadores" (BRAVO; PELAEZ; PINHEIRO, 2018, p. 12). Este Estado limita-se então a ser um agente repassador/facilitador de verba pública e outras medidas que favorecem o setor privado, melhor dizendo, o capital.

Na esteira do capitalismo dependente, o Brasil intensifica a adesão à agenda ultraneoliberal, por meio de ações concretas concertadas entre governos federal e estaduais $^{10}$. Como consequência, o setor público se descompromete cada vez mais, total ou parcialmente, com o atendimento aos direitos e obrigações constitucionais, explícitas na Constituição Federal de 1988 (FRENTE EM DEFESA DA UERJ PÚBLICA, 2017, não paginado).

Ao falar sobre o governo Temer queremos apontar os retrocessos para a sociedade brasileira nos diferentes campos da vida social: do meio-ambiente, com aumento do desmatamento, a questão da Amazônia, das mineradoras (a maioria de capital e origem transnacional), impondo sua forma de exploração das riquezas e intensa exploração do trabalho, provocando acidentes ambientais, destruindo rios e sua população local, o domínio do agronegócio em detrimento da agricultura familiar, a ameaça da venda do Aquífero de Guarani, a mercantilização da água, a tentativa de alteração da legislação do trabalho análogo ao trabalho escravo, a política de Direitos Humanos, dentre inúmeras outras, que de forma direta ou indireta, afetam a saúde. É neste período que temos um retrocesso ideopolítico aberto, em que o pensamento único quer se impor e o conservadorismo e reacionarismo se reforçam.

A aprovação da Lei da Terceirização e da Reforma Trabalhista é emblemática do que estamos tratando aqui. Allan (2016, p. 332) ao abordar sobre estas recentes legislações lembra que havia um Estado brasileiro, em um certo tempo histórico, onde apesar da burguesia tentar findar com o paradigma do direito do trabalho, não conseguiu, posto que a correlação de forças entre capital e trabalho não permitiu. No entanto, no governo de Temer,

A Reforma Trabalhista de hoje significa a ausência de freios à exploração dos trabalhadores [...] - o fim do direito do trabalho como conhecíamos - PLC 30/2015 - Lei da Terceirização - com o objetivo de terceirizar todas as atividades de uma empresa,

9 Exposição do autor durante participação no XV Encontro Nacional de Pesquisadores do Serviço Social, de 2016.

${ }^{10}$ No estado do Rio de Janeiro, para o setor Saúde, o governo de Sérgio Cabral (2007-2014/PMDB) aprovou a Lei 5164 de 17 de dezembro de 2007, que autoriza instituir as "Fundações Estatais dos Hospitais Gerais [...] (mantidas no governo de Luiz Pezão - 2014-PMDB). E Eduardo Paes (2009-2016/PMDB), por meio da Lei 5586 de 28 de maio de 2013 - cria a Empresa de Saúde do Rio de Janeiro a RIOSAUDE.

Argum., Vitória, v. 10, n. 1, p. 33-50, jan./abr. 2018. 
o que induz à precarização das condições de trabalho e a potencialização dos lucros do capital (ALLAN, 2016, p. 333).

\section{AS CONTRARREFORMAS DA POLÍTICA DE SAÚDE NO GOVERNO TEMER}

Como podemos perceber ao longo do texto de Bravo, Pelaez e Pinheiro (2018) e de nossas complementações, se o governo Temer instalou-se no poder para responder às demandas urgentes do capital, os processos de contrarreforma do Estado se aceleram cada vez mais, a área da Saúde é um dos nichos de lucro a ser mais explorado. Lembremos que os usuários do SUS são em torno de $75 \%$ da população. Portanto, são os trabalhadores os mais atingidos, principalmente quando temos um ministro afirmando que "[...] o país não poderá garantir o acesso universal à saúde, como previsto na Constituição Federal de 1988” (COLLUCCI, 2016,). É Inusitado/novo, que um cidadão ao assumir um cargo público, não defenda o sistema público" ${ }^{11}$.

Na verdade, podemos afirmar que as medidas tomadas por Temer, qualquer governo de cunho neoliberal, poderia colocar na mesa. O documento Uma ponte para o Futuro, apresentado em 2015, com as propostas do PMDB para "[...] enfrentar a crise política e econômica, destinando-se [...], a preservar a economia e tornar viável o desenvolvimento” [...] (FUNDAÇÃO ULLYSSES GUIMARÃES, 2015), já revela a luta interna com o governo petista e a intensificação da luta nos blocos de poder. Nesse documento estão postas as contrarreformas da Previdência Social, a redução em investimento nas políticas prioritárias, como Educação e a Saúde, exatamente o oposto do caminho para o país desenvolver. Este documento é ratificado no governo Temer, com medidas (todas) de cunho privatista, com destaque para o fim das "[...] vinculações institucionais, como no caso da Saúde e Educação [...]" (FUNDAÇÃO ULLYSSES GUIMARÃES, 2015), demonstrando como a contrarreforma do Estado mantém o curso do desmonte da CF/88.

Na contramão do SUS, o ministro da saúde "[...] apresenta a proposta dos denominados Planos de Saúde Populares (BRAVO; PELAEZ; PINHEIRO, 2018, p. 14). Em documento oficial, a justificativa para sua criação seria a da "[...] redução de cerca de 1,5 milhões de pessoas que deixaram de fazer uso de planos privados em 2016, devido à recessão econômica e à elevada taxa de desemprego" (BRAVO; PELAEZ; PINHEIRO, 2018, p. 14). Seria o caso de a instituição governamental procurar aprimorar o sistema público (SUS), para receber mais esta população e não abrir espaço para redução de danos das empresas de planos de saúde ${ }^{12}$. No entanto, em sentido contrário, para solucionar o problema do setor privado, o governo Temer responde de forma direta às necessidades do mercado de planos de saúde para se recomporem

\footnotetext{
${ }^{11}$ Aqui atualizamos a informação sobre o apoio financeiro a Ricardo Barros enquanto candidato a deputado federal pelo Paraná. O Grupo Aliança foi vendido para o grupo QUALICORP (que compõe a COALIZAÇAO BRASIL SAÚDE), elaboradora da Agenda para transformar o sistema de Saúde, 2017. Seu proprietário está na lista dos homens mais ricos do Brasil, apesar de sua origem modesta, tendo criado o grupo em torno de 1997. Completando, segundo Farias (2016), estudos do IBGE (2016) apontam que “[...] o único setor que não sofreu queda nas vendas em 2015 foi o de artigos farmacêuticos, médicos, ortopédicos, perfumaria e cosméticos, que cresceu 3\%. Quanto às Administradoras de Planos de Saúde: a Qualicorp teve lucro de R\$ 61,4 milhões no último trimestre de 2015, apresentando avanço de $\mathbf{2 2 4 \%}$ em relação ao mesmo período de 2014" (FARIAS, 2016, não paginado, grifo nosso).

${ }^{12}$ Segundo Oliveira (2015) do jornal Valor Econômico, com base em estudos de Mário Scheffer (USP) e Lígia Bahia (UFRJ), a Qualicorp foi a "[...] administradora do segmento de planos de saúde a financiar diretamente, as duas principais campanhas presidenciais da última eleição" (OLIVEIRA, 2015, não paginado).
}

Argum., Vitória, v. 10, n. 1, p. 33-50, jan./abr. 2018. 
de suas perdas, pois querem expandir a sua média de $25 \%$ de clientela, ainda que estes paguem valores bem menores e só para alguns serviços (produtos, na linguagem mercadológica) e ainda sem garantia de qualidade total. Trata-se de considerar a Saúde como uma mercadoria. Desse modo, concorda-se com o sentido dado por Antunes (2016), um governo terceirizado, que segue o que está posto tanto pelas agências financeiras internacionais, quanto reponde à pressão do setor privado no país, ou seja, predomina claramente o Projeto privatista (o projeto burguês).

Lembramos ainda que é no governo Temer foi aprovada a PEC 95/2016, congelando os investimentos públicos por 20 anos. Congela também os salários dos atuais servidores e proíbe o concurso público, atingindo diretamente os jovens profissionais do setor e os $75 \%$ usuários do SUS.

Seguindo o sentido de seu trabalho, os autores selecionam o documento Travessia Social, de abril de 2016, mostrando que o PMDB simbolicamente, pensava de acordo com a agenda do PSDB (MARE/95). No documento, percebe-se a coerência política da macroeconomia, como a contenção da inflação e a necessidade do ajuste fiscal (sinônimo de retirar mais direitos dos trabalhadores, cortando nas políticas sociais); fala da necessidade de redução da inflação às metas do Banco Central e na volta do equilíbrio fiscal, sinônimo de corte nas despesas públicas. Acrescenta a importância da transferência do fundo público para o setor privado, quando apresenta seus objetivos: "[...] identificar oportunidade de colaboração com o setor privado, para desenvolver parcerias público-privadas com compartilhamento de riscos operacionais e financeiros, para estimular aumentos de produtividade e ganhos de eficiência" (FUNDAÇÃO ULLYSSES GUIMARÃES, 2016). Desse modo, ao assumir a retirada do Estado de seus compromissos constitucionais e a passagem de suas funções para o capital, o documento Travessia Social registra que "[...] o Estado deve transferir para o setor privado tudo o que for possível” (FUNDAÇÃO ULLYSSES GUIMARÃES, 2016).

No campo da Saúde (SUS), mantém o argumento da má administração, e a saída também: a ênfase no gerencialismo. E por fim, o ultraneoliberalismo se impõe com mais veemência: “[...] a necessidade de focalização na parcela que não pode pagar planos privados de saúde e o estímulo ao aumento de sua cobertura" (BRAVO; PELAEZ; PINHEIRO, 2018, p. 13). DE fato, estas medidas em sua essência já se encontram nos Cadernos do MARE ${ }^{13}$ (1995). Só não definiam que a focalização das ações poderia ser mensurada em um percentual (os 40\% mais pobres da população pobre).

No texto, os autores (BRAVO; PELAEZ; PINHEIRO, 2018), problematizam o financiamento na área da saúde (com dados do IPEA, 2016), apontando a seriedade com que esta questão tem que ser tratada, pois a tendência é de um maior agravamento do que já está extremamente sucateado, precarizado. Se estudiosos já demonstravam o subfinanciamento histórico do setor Saúde, a medida apresentada no documento Travessia Social, acentuará mais o já subfinanciado SUS, como os autores apontam. Inevitavelmente, isto pode induzir uma parte da população por necessidade e não por opção, a recorrer a planos privados. Consequentemente, mantém-se assim, a política de facilitar a inserção nos planos privados e a intenção

13 O MARE produziu 18 Cadernos para definir e operacionalizar as contrarreformas do Estado brasileiro e um especial para a Saúde (TEIXEIRA, 2010b).

Argum., Vitória, v. 10, n. 1, p. 33-50, jan./abr. 2018. 
de cobrar os serviços prestados. Poderá restar de tal modo, um número cada vez menor de brasileiros a utilizá-lo, eliminando então a universalidade da atenção, caminhando para a concretização da intenção do ministro atual.

Os autores demonstram em números, como a contrarreforma na Saúde vai se materializando no governo Temer, com redução expressiva do orçamento e a revisão de duas políticas nacionais centrais: a revisão da Política de Atenção Básica (pautada em reunião da cúpula ministerial) e a de Saúde Mental. Acrescenta-se aqui a postura antidemocrática ao não inserir o Conselho Nacional de Saúde (CNS) nos espaços de decisão sobre as mesmas, denotando que este governo não reconhece tal instância como espaço de decisão, como uma ferramenta que compõe uma das diretrizes do SUS (BRASIL, 2006a.). Certamente, sua ausência se justifica também pela visão crítica que o CNS tem construído e mantido, buscando sua autonomia governamental, colocando-se historicamente contra a privatização/mercantilização do setor (CORREIA, 2009). Trata-se, nesta revisão, de centrar o debate nas formas de financiamento para outros arranjos assistenciais que não contemplem equipes multiprofissionais, com a presença de Agentes Comunitários de Saúde (ACS) (FEDERAÇÃO NACIONAL DE ACS E ACE, 2018). Em 23 de março de 2018, foi realizada reunião em Brasília, organizada pela Comissão Intersetorial de Recursos Humanos e Relações de Trabalho do CNS. O objetivo deste encontro foi exatamente o de identificar os impactos às relações de trabalho para os ACS e Agente Comunitário de Combate às Endemias (ACE), após a publicação da Portaria $2436 / 2017$.

Para os estudiosos e para os militantes da Saúde, os dados são reveladores do desemprego e desqualificação destes profissionais, que esta medida provoca. Em meados de março de 2018 temos informações que ratificam nossos argumentos: 300 demissões de ACS e ACE na região do ABC paulista; em Santos: 164 ACS e no Rio de Janeiro: cerca de 100, com notícias de demissão em massa também em Sergipe e Espírito Santo (Federação Nacional de ACS e de Combate às Endemias (FENASCE), 2018.

Como Bravo, Pelaez e Pinheiro (2018, p. 16) apontam, o documento Travessia Social, 2016, denota a configuração de uma "[...] política focalista e restrita às populações mais vulneráveis ou agravos mais comuns, limitando-se à oferta do mínimo do mínimo". O referido documento ousa propor atingir a meta de $40 \%$ entre os mais pobres dos já pobres. Isto significa que uma grande parcela, cerca de $60 \%$ dos pobres serão excluídos e os setores médios, e os trabalhadores de diferentes extratos, deverão recorrer aos planos privados. Esta realidade reafirma o caminho do desmonte do que já estava precário, não se tratando, pois, de um ajuste/revisão, de um futuro incerto, mas a certeza de que o mecanismo montado para alterar a configuração do que foi construído é reafirmar a primazia do privado sobre o público.

Outro item que nos chama a atenção é a estipulação da redução da carga horária de trabalho, que pode chegar a $10 \mathrm{~h}^{14}$. Sabemos que esta redução pode ser deletéria tanto do ponto de vista do usuário, quanto para o trabalhador, visto que isso significa para o profissional de saúde, em média dois a três dias de presença concreta na Unidade de Saúde [um turno com-

\footnotetext{
14 Aproxima-se do hoje é imposto na pelas Organizações Sociais que administram as unidades de saúde da prefeitura (Clínicas da Família, por exemplo), no Rio de Janeiro, com deslocamento dos profissionais de saúde de uma unidade para outra, em dias de trabalho diferentes, em bairros diferentes.
}

Argum., Vitória, v. 10, n. 1, p. 33-50, jan./abr. 2018. 
pleto, ou/e dois/três turnos), com baixos salários e a possibilidade de dupla/tripla jornada em diferentes unidades. Certamente, esta reorganização dos serviços na atenção básica será deletéria para a qualidade do atendimento, tanto do ponto de vista do usuário, quanto do trabalhador da saúde. Como ficaria a busca ativa com carga horária tão restrita? Como ficaria o trabalho minucioso de contato direto com as famílias do campo territorial de atuação, ou seja, como se daria a prevenção e promoção da saúde?). Este tempo de trabalho não permite um planejamento que contemple as tarefas que combinam trabalho interno e externo, como acompanhamento dos casos a partir da singularidade dos sujeitos e o trabalho coletivo com a comunidade e com a equipe. Como corresponder às diretrizes e aos princípios do SUS para este nível de atenção? (TEIXEIRA, 2014).

Do ponto de vista do profissional (os que ainda ficarem), este tempo escasso de trabalho tenderá a provocar a intensificação da jornada de trabalho, o que também limita a atenção adequada, provocará tensões no desempenho das tarefas e possíveis conflitos entre si e com a comunidade, deteriorando as relações de trabalho, trazendo desgaste físico e emocional aos mesmos, que por óbvio, rebaterá no usuário. Acrescentamos a perspectiva de dificuldade quanto à organização e luta dos profissionais de saúde em suas respectivas entidades de classe (TEIXEIRA, 2014).

A seguir, é importante destacar a revisão feita na Política Nacional de Saúde Mental'5, a qual vinha em um processo gradativo de avanços e conquistas. A Portaria 3.588/2017 representa a interrupção do mesmo, no contraponto do favorecimento à lógica da internação hospitalar e certamente com verba pública (a parceria público-privada). O questionamento se amplia e se soma à forma como o Ministério da Saúde trata: sem consulta ao CNS e ao Movimento Nacional de Luta Antimanicomial, cuja posição é explicitamente contrária às alterações impostas pelo órgão público. Esta postura antidemocrática aparece como um Estado hoje apartado da sociedade civil, sem diálogo, sem troca e decidindo a partir de seus pares, próprio do que se denomina como a ideologia ultraneoliberal.

Os autores, baseados em seus estudos e método de análise, afirmam que o Estado capitalista, em sua fase contemporânea de financeirização, responde mais às necessidades do capital do que do trabalho, mostram como este movimento ocorre. No âmbito da Saúde, o artigo nos informa que o projeto do capital está bem articulado e tem o Estado como seu parceiro fiel para aprovação de suas propostas. Vimos a partir deste artigo, que o Instituto Coalização Brasil, em entidade criada em 2014, engloba os representantes do setor empresarial, apresenta sugestões em defesa de seus interesses a serem absorvidas, encampadas, pelo governo federal. Assim, produz o documento Coalização Saúde Brasil: uma agenda para transformar o sistema de saúde, recém-divulgado (2017).

\footnotetext{
15 O movimento social na especialidade da Saúde Mental tem uma longa trajetória de luta, sobretudo no período da ditadura militar, de resistência e debate posicionando-se contra as internações em manicômios e correlatos, lutando contra a forte presença do setor privado na área, entre outras lutas específicas. Este movimento acompanhou o movimento da Reforma Psiquiátrica italiana nos anos de 1970/80 e construiu as propostas para o Brasil, incorporadas na elaboração do SUS/90. A Política Nacional de Saúde Mental que cria os CAPs e as demais ações governamentais que ampliam a cobertura assistencial em ambulatórios, foram produto desta luta que se faz presente até a atualidade.
} 
A composição desta entidade é espelho do debate aqui estimulado: são os grupos pertencentes ao complexo médico-industrial-financeiro. Sua finalidade maior é alargar a capacidade de realização do capital, ou seja, acumular mais lucros. Para atingir seus propósitos, em aparente contradição, os ultrasneoliberais precisam do Estado, tanto para aprovar (no campo do legislativo e do jurídico) suas propostas, quanto para liberar recursos públicos (financiamento a juros baixos/acordados, entre outras facilidades), o que instiga mais a luta de classes, visto que o movimento social organizado, em defesa do SUS se fará presente. Este é o cenário da luta em alguns momentos latentes ou em outros manifestos, entre os projetos da reforma sanitária e o projeto privatista.

Entretanto, mantemos o entendimento de que o governo Temer, embora com nuances, em função das condições sócio-históricas, segue a agenda PSDB (Banco Mundial/OCDE), mantendo a lógica do MARE ${ }^{16}$ (utilizando-se inclusive de algumas legislações do mesmo período FHC). Lembramos então que as Organizações Sociais (OSs) já estão presentes contratando servidores, administrando as unidades públicas nas diferentes esferas de governo e a EBSERH foi implantada nos hospitais universitários de algumas universidades públicas. A diferença preocupante por nós encontrada no documento "Coalização Brasil [...]" é por tratar-se da (re)composição do setor privado da Saúde articulado ao setor produtivo (FIESP) paulistano inicialmente, na liderança. Sendo assim, as sugestões são mais ousadas, pois assumidamente propõem um sistema de Saúde que quer negar a existência do SUS e tirá-lo de cena de vez, ainda que se refira à "[...] necessidade de os setores público e privado precisarem construir uma rede integrada de cuidados contínuos" (FEDERAÇÃO NACIONAL DE ACS E ACE, 2018, não paginado). Um tanto vago, mas ainda considera sua existência. No entanto, a integração significa a gestão estar em mãos do setor privado. Curiosamente, a entidade reúne-se e lança sua tese em espaço de uma Universidade pública ${ }^{17}$.

Algumas questões do documento "Coalizão Brasil [...] nos chamaram a atenção, embora consideremos suas propostas contraditórias, quando se referem a um fortalecimento da atenção primária, por exemplo. Como seria este fortalecimento, se o governo Temer, com sua mais recente portaria, desmontou este nível de atenção? Como ampliariam o acesso ao medicamento, de acordo com a proposta, se o governo Temer reduziu o número de farmácias populares? Lembramos que, não obstante estes documentos e propostas apresentaremse com o discurso do novo, foram os governos militares que abriram este espaço de poder ao capital na área da Saúde, o qual cresceu, considerando a economia financeirizada hoje e a direção política que o país teve ao longo dos governos pós redemocratização. A questão pertinente que mais caracteriza o avanço do setor privado é a extensão de seus espaços de domínio também no aparelho de Estado.

Nesta direção, destacamos a proposta de alteração quanto à composição, espaço territorial e função dos Conselhos de Saúde. Os novos componentes serão "[...] especialistas e ligados ao gabinete dos prefeitos [...]” (COALIZÃO SAÚDE BRASIL, 2017), e em âmbito nacional, seria um Conselho Executivo, também composto por especialistas, com poder decisório (grifo nosso). Ou seja, elimina a participação social (o controle social) prevista no SUS e o Ministé-

\footnotetext{
${ }^{16}$ Seguindo o PDRE/95, a análise continua sendo a má gestão e a forma de enfrentamento seria através do setor privado, em parceria, tido como novo modelo de governança.

${ }_{17}$ Ainda que a Faculdade de Medicina da USP utiliza-se da parceria público-privado há algumas décadas.
}

Argum., Vitória, v. 10, n. 1, p. 33-50, jan./abr. 2018. 
rio da Saúde (inclusive o Conselho Nacional de Saúde como hoje está previsto) teria seu poder diluído (coerente com o neoliberalismo: sem cidadania).

Se as ações do governo Temer, representam o retrocesso na Atenção Básica, na Política de Saúde Mental entre outras políticas, e em especial no controle social como questão pétrea do SUS, ele prepara o terreno para os planos privados darem a cobertura que o setor público (SUS) não conseguirá. Como? Entre uma das propostas facilitadoras seria a alteração da legislação dos Planos de Saúde, criando os modestos Planos Populares. Não é o acaso que escolhe um deputado do PSDB para ser o relator da Comissão Especial sobre estes Planos de Saúde, é a articulação ideológica, político-partidária que o define. Podemos até não saber exatamente quais serão as propostas, mas sabemos a quem elas beneficiarão, para quem estão sendo dirigidas ${ }^{18}$.

O estudo das propostas de mudanças nos Planos de Saúde (dezembro de 2017) advindas da Câmara dos Deputados reforça o entendimento de que o governo Temer escolheu o caminho que privilegia as empresas de planos e seguros de Saúde, em detrimento das necessidades, possibilidades e direitos da maioria da população brasileira. Propõe alterar o Estatuto do Idoso, com a permissão de aumentos para este segmento social, protegido pelo Estado até o momento, como grande conquista da Política de Seguridade Social na CF/88, como igualmente a regulamentação dos planos. Estas definições políticas foram fruto de muita luta dos movimentos sociais nos campos da Saúde e da Assistência Social.

Na verdade, não podemos nos surpreender, pois Temer dá seguimento ao que não conseguiu ser aprovado entre 1994-2002, quando o PT era oposição forte ao neoliberalismo e as lutas sociais impediram algumas contrarreformas. Também os governos petistas, por seu perfil inicial no campo democrático-popular evitou conduzir algumas contrarreformas, apesar de ter conduzido outras, na área da Saúde inclusive, como apontado no texto de Bravo et all, 2018 e neste trabalho.

Por conseguinte, resta ao presidente atual, deixar as contrarreformas prontas para o subsequente, de qualquer campo ideopolítico que seja, ${ }^{19}$ pretendendo deixar, pois, garantido ao capital seus superlucros (MANDEL, 1982). Esta deve ser a justificativa para o regime de urgência. As decisões são políticas (em ano de eleições há pressa). Entretanto, como "tudo que é sólido se desmancha no ar" ${ }^{20}$... temos um movimento social se fortalecendo e esta disputa não se esgotou e certamente será intensa.

\footnotetext{
18 Como complemento, informamos que o atual ministro Ricardo Barros se desincompatibilizou do cargo para candidatar-se. Em abril de 2018 temos novo ministro da saúde no governo Temer: Gilberto Occhio, presidente da Caixa Econômica Federal (desde 2014).

19 Temer sinaliza sua possível candidatura à presidência em 2018.

${ }_{20}$ Marx e Engels (2003, pp. 4-5)“Tudo que é sólido se desmancha no ar, tudo que é sagrado era profanado e as pessoas são finalmente forçadas a encarar com serenidade sua posição social e suas relações recíprocas". Seguindo esta máxima, entendemos que o governo Temer foi obrigado a recuar e retirar a votação de pauta no Congresso Nacional, da proposta de alterações na Previdência Social, em janeiro de 2018. Houve um grande Ato Público em Brasília, com mobilização nacional e o governo respondeu com intensa repressão.
}

Argum., Vitória, v. 10, n. 1, p. 33-50, jan./abr. 2018. 


\section{Considerações Finais}

Parabenizamos os autores pela iniciativa em trazer à tona o tema, em forma de artigo, ousando enfrentar o desafio de escrever a história no momento em que ela está se processando. A concretude das mudanças na política nacional de saúde hoje, atinge a classe trabalhadora de forma intensa (a barbárie) e é preciso acumular forças para resistir e reverter este quadro. $\mathrm{O}$ artigo atinge seu objetivo ao mostrar com pertinência e clareza, a perspectiva da contrarreforma do Estado, na política de saúde imposta pelo governo Temer. Um textomilitante, com força na luta, sem esmorecer, entendendo que a sociedade capitalista é dinâmica e plena de contradições.

Como pudemos observar ao longo de nosso trabalho, convergimos nos principais pontos, apenas levantando algumas questões/reflexões, à guisa de contribuir para o debate com o objetivo maior de construir pontos que permitam avançar na elaboração de táticas mais próximas da estratégia maior: uma luta em defesa da Saúde pública, de qualidade, socialmente referenciada, combinada com a luta anticapitalista.

Nesta direção, consideramos que informação é poder, dessa forma, percebemos que o texto apresentado pelos autores (BRAVO; PELAEZ; PINHEIRO, 2018), contribui tanto para o espaço acadêmico, quanto para os movimentos sociais, em especial o da Saúde, pois o instrumentaliza para a luta em defesa da manutenção da política de saúde constitucional, ainda que em condições adversas, como a atual.

Sabe-se que Temer buscou nos poderes do Estado, a legitimidade que não teve pelo voto. Desse modo, para garantir a governabilidade, aliou-se com as bancadas ruralista, evangélica, industrial, financeira, entre as demais, como ainda contou com parte da mídia e o poder judiciário, ou seja, com segmentos sociais que representam o atraso social, cultural e econômico no país. Com um governo baseado na concepção ultraneoliberal, a classe trabalhadora tem o poder Executivo cada vez mais alheio às suas demandas. E para efetivar seu projeto, este executivo utiliza o aparelho de Estado, inclusive as forças militares para reprimir o movimento social organizado.

Assim, o governo Temer segue priorizando o Projeto do capital na sociedade brasileira ${ }^{21}$ e aqui destacamos a Saúde, ao apresentar suas propostas em articulação com os segmentos da classe dominante, desconsiderando os espaços democráticos constitucionais para o debate e direção política (Conselhos e Conferências de Saúde). Sabemos que, na sociedade capitalista, tanto a burguesia, quanto os trabalhadores, por meio de suas entidades, se organizam para apresentar e defender suas propostas que podem ser de manutenção ou de mudanças. A diferença principal é que a burguesia tem os poderes do Estado a seu favor, acentuada na fase de domínio ultraneoliberal.

Como vimos, a privatização das políticas sociais e a política de saúde em particular, já advêm desde os tempos da ditadura militar, em fluxo contínuo, apesar de passar por alguns (breves)

${ }^{21}$ Podemos consultar alguns projetos novos e os retomados pelo governo Temer relacionados às áreas da Educação, Saúde e outras políticas sociais, como: a PEC 287/2016, o PL 6787/2016, PLS 339/2016 e busca recuperar os PLS 4302/1998, o PLC 30/2015 e seus correlatos (PLS87/2010, PLS300/2015), não aprovados naquelas conjunturas SN-ANDES, 2017.

Argum., Vitória, v. 10, n. 1, p. 33-50, jan./abr. 2018. 
momentos de recuo (ou certo controle/intervenção do Estado). No mundo contemporâneo, da fase financeirizada do capital, com um governo "terceirizado ${ }^{22}$ " e de refluxo dos movimentos sociais (com a reestruturação produtiva: desemprego, trabalho precário, a terceirização, a retirada de direitos trabalhistas, previdenciários, a despolitização da sociedade, a criminalização dos movimentos sociais, como também a burocratização de alguns), ou seja, entre outras razões, pelo acirramento das expressões da questão social, estas políticas estão perdendo suas possibilidades de cumprirem seu papel constitucional.

Para que a Saúde fosse, de fato, mais um produto a ser oferecido no mercado, (com a necessária presença do Estado), tornou-se necessário um representante completo, no âmbito do Estado, que respondesse, sem limites, às demandas dos superlucros. Ele se personifica em Michel Temer e seus aliados nos diferentes segmentos burgueses no Brasil (e internacionalmente). A questão pertinente, que mais caracteriza o avanço do setor privado, é a extensão de seus espaços de domínio também no aparelho de Estado.

No caminho de aglutinar forças e avançar com propostas concretas e pressão social em defesa da saúde pública, muitos fóruns de luta foram criados, em âmbito local e nacional, como os autores apontam, principalmente após a segunda metade dos anos de 1990 e após os anos 200o, respondendo e enfrentando a hegemonia neoliberal que se instalou naquele período e consolidou-se com o ultraneoliberalismo em sua fase presente.

Em sentido contrário à esta avassaladora e ameaçadora direção, o texto de Bravo, Pelaez e Pinheiro (2018) desponta com força, entendendo que a sociedade capitalista é dinâmica e que o caminho só pode ser o da luta. E que ela seja permanente e unificada. Deste modo, traz à luz propostas avançadas para esta conjuntura, mas essenciais para manter vivo o horizonte de conquistas e mudanças da realidade social, presentes no PRS.

É ponto pacífico, considerar que a conjuntura dos anos de 1980 é outra e a correlação de forças também. Coadunamos ainda com o entendimento de que o texto constitucional/1988 foi um marco para a classe trabalhadora brasileira, mas tem seus limites: o da correlação de forças na luta de classes. Como tem limites a condução da luta institucional ${ }^{23}$. Nesta direção, entendemos que os movimentos sociais precisam encontrar seus próprios caminhos e um deles penso que pode ser a urgente "[...] necessidade de politização da saúde com o objetivo de aprofundar a consciência sanitária” (BERLINGUER apud BRAVO; PELAEZ; PINHEIRO, 2018, p. 19). No entanto, não conseguimos perceber um grau de consciência em um único setor (só a Saúde), de uma única política social, separada das questões gerais, da questão

\footnotetext{
${ }^{22}$ Quando afirmamos que a relação de subalternidade associada ao grande capital permanece no Estado brasileiro, recomendamos a leitura do recente Relatório do Banco Mundial, onde o mesmo, foi solicitado pelo governo brasileiro e entre uma de suas análises considera que "[...] o gasto tornou-se cada vez mais engessado pela rigidez constitucional em categorias como folha de pagamento e previdência social" [...] [grifo nosso], ou seja, ainda segue a lógica do Estado preso à Constituição Federal/88, onde os salários a Previdência Social são responsáveis por nossos "gastos" (BANCO MUNDIAL, 2017, p. 5, grifo nosso) O mesmo documento segue afirmando que [...] a fonte mais importante da economia fiscal ao longo prazo é a Reforma da previdência e apresenta suas recomendações de como e onde deve ser feito (BANCO MUNDIAL, 2017, p. 1213). Mais adiante considera fundamental a "[...] retirada de privilégios de servidores públicos contratados antes de 2003 [...] e chama a atenção em permanecer o foco nas populações mais vulneráveis (BANCO MUNDIAL, 2017, p. 16).

23 Talvez o erro crucial do PT, caso realmente pretendesse avançar nas conquistas da classe trabalhadora.
}

Argum., Vitória, v. 10, n. 1, p. 33-50, jan./abr. 2018. 
nacional e da internacional. Sinalizando que entendemos não ser esta também a percepção dos autores.

Pensamos que se é o modo de produção capitalista, na sua fase atual de priorização da acumulação prioritariamente por meio das finanças, provocando redução de emprego, baixos salários (inerente ao seu processo), terceirização da força de trabalho, retirada dos direitos e captura da consciência (subjetividade) dos trabalhadores (ALVES, 2011), é contra ele que devemos lutar. Qualquer que seja o governante do momento, neste país, se a correlação de forças não for mudada (e não será pelo voto), as condições de vida, saúde e trabalho da classe trabalhadora se alterarão.

A defesa da Saúde com as propostas avançadas apresentadas no artigo, entendemos que deve ser combinada com a luta anticapitalista (enquanto projeto de classe), e em nosso entendimento, as vertentes reformista e a social-democrata (incluindo o projeto democráticopopular), não assimilaram esta concepção.

Seguindo os clássicos da teoria social crítica, a luta anticapitalista e a construção da sociedade socialista, passam pela criação de um partido revolucionário da classe trabalhadora. Talvez já seja o momento de pensarmos na sua criação. Aí sim, poderemos ter uma política de saúde não mercantilizada e respondendo aos interesses, necessidades e direitos da classe trabalhadora.

\section{Referências}

ALLAN, N. Para depois do golpe: o ataque aos direitos dos trabalhadores. In: PRONER, C.; CITTADINO, G.; TENENBAUM, M.; RAMOS FILHO, W. [Orgs.]. A resistência ao golpe de 2016. Bauru: Canal 6; Projeto Editorial Praxis; Instituto Defesa da Classe Trabalhadora, 2016. p. 331-334.

ALVES, G. Trabalho e subjetividade: o espírito do toyotismo na era do capitalismo manipulatório. São Paulo: Boitempo, 2011.

ANDRADE, M. A. De Marx a Mèszaros: a inseparável relação entre o Estado e a reprodução do capital. In: PANIAGO, M. C.; MELO, E.; ANDRADE, M. (Org.). Marx, Mészaros e o Estado. São Paulo: Instituto Lukács, 2012. p. 11-29.

ANTUNES, R. A destruição do trabalho e o serviço. Mesa Temática dos Grupos de Trabalho e Pesquisa. In: ENCONTRO DE PESQUISADORES DE SERVIÇO SOCIAL (ENPESS), 15.; 2016. Anais... São Paulo, 4-8 dez. 2016.

BANCO MUNDIAL. Um ajuste justo: Análise da eficiência e equidade do gasto público no Brasil: Brasil: revisão das despesas públicas. v.I: Síntese. Whasington (DC), nov. 2017.

BRASIL. Presidência da República. Lei no 13.097, de 19 de janeiro de 2015. Reduz a zero as alíquotas da Contribuição para o PIS/PASEP, da COFINS, da Contribuição para o PIS/Pasep-Importação e da Cofins-Importação incidentes sobre a receita de vendas e na importação de partes utilizadas em aerogeradores; [...]. Brasília (DF), 2015. Disponí-

Argum., Vitória, v. 10, n. 1, p. 33-50, jan./abr. 2018. 
vel em: <http://www.planalto.gov.br/ccivil_03/_ato2015-2018/2015/lei/l13097.htm>. Acesso em: 4 abr. 2018.

BRASIL. Presidência da República. Lei no 12.550, de 15 de dezembro de 2011.

Autoriza o Poder Executivo a criar a empresa pública denominada Empresa Brasileira de Serviços Hospitalares - EBSERH; acrescenta dispositivos ao Decreto-Lei no 2.848, de 7 de dezembro de 1940 - Código Penal; e dá outras providências. Brasília (DF), 2011. Disponível em: <http://www.planalto.gov.br/ccivil_03/_ato20112014/2011/lei/l1255o.htm>. Acesso em: 24 jan. 2016.

BRASIL. Ministério da Saúde. Portaria no 399, de 22 de fevereiro de 2006. Pactos pela saúde. Consolidação do SUS e Aprova as Diretrizes Operacionais do Referido Pacto. Diário Oficial [da] República Federativa do Brasil, Poder Executivo, Brasília (DF), 20o6a. Seção 1, p. 14.

BRASIL. Presidência da República. Lei no 8142, de 28 de dezembro de 1990. Dispõe sobre a participação da comunidade na gestão do Sistema único de Saúde (SUS) e sobre as transferências governamentais de recursos financeiros na área da saúde e dá outras providências. Diário Oficial [da] República Federativa do Brasil, Poder Executivo, Brasília (DF), 1990. Seção 1, p. 25694.

BRASIL. Ministério da Saúde. Conheça o novo ministro da saúde Gilberto Occhi. Blog da Saúde, Brasília (DF), 2 abr. 2018. Disponível em:

<http://www.blog.saude.gov.br/index.php/53289-conheca-o-novo-ministro-gilberto-occhi>. Acesso em: 4 abr. 2018.

BRASIL. Ministério da Saúde. Portaria no $\mathbf{3 5 8 8 / 2 0 1 7}$. Altera as Portarias de Consolidação no 3 e no 6, de 28 de setembro de 2017, para dispor sobre a Rede de Atenção Psicossocial e dá outras providências. Disponível em:

<httpp://www.brasilsus.com/br/imagens/portarias/dezembro/2017/dia22/portaria 3588.pdf >. Acesso em: 4 abr. 2018.

BRAVO, M. I. S., PELAEZ, PINHEIRO. As contrarreformas na política de saúde no governo Temer. Argumentum, Vitória, v. 10, n. 1, p. 9-23, jan./abr. 2018.

CORREIA, M. V. C. Controle Social na Saúde. In: MOTA, A. E. et al. (Orgs.). Serviço Social e Saúde: formação e trabalho profissional. 4. ed. São Paulo: Cortez, 2009. p. 111-138.

COSTA, M. O mais novo bilionário da bolsa. Jornal O Estado de São Paulo, São Paulo, 11 jul. 2011. Disponível em: <http://economia.estadao.com.br/noticias/geral,o-mais-novobilionario-da-bolsa-imp-,743233>. Acesso em: 28 mar. 2018.

COLLUCCI, C. Tamanho do SUS precisa ser revisto, diz novo ministro da Saúde. Folha de São Paulo, São Paulo, 17 maio 2016. Disponível em:

<httpp:/www.uol.com.br/cotidiano/2016/o5/1771901 - tamanho-do-sus-precisa-ser-revistodiz-novo-ministro-da-saúde-shtml>. Acesso em: 23 mar. 2018. 
FARIAS, Leandro. Indústria da doença, lucro vertiginoso. Le Monde Diplomatique, São Paulo, p. 30, 6 jun. 2016. Disponível em: <http:// www.economia.estadao.com.br/noticias/geral>. Acesso em: 28 mar. 2018.

FEDERAÇÃO NACIONAL DE ACS E ACE. Entrevista. Mar. 2018. Disponível em: <http://www.susconecto.org.br>. Acesso em: 26 mar. 2018.

FERNANDES, F. Que tipo de República? São Paulo: Brasiliense, 1986.

FRENTE EM DEFESA DA UERJ PÚBLICA. Manifesto de Outubro de 2o17. Rio de Janeiro, 2017.

GENRO, T. Agonia e êxtase do liberalismo decadente. In: PRONER, C.; CITTADINO, G.; TENENBAUM, M.; RAMOS FILHO, W. (Orgs.). A resistência ao golpe de 2o16. Bauru: Canal 6; Projeto Editorial Praxis; Instituto Defesa da Classe Trabalhadora, 2016. p. 388-392.

GRAMSCI, A. Obras Escolhidas. São Paulo: Martins Fontes, 1978.

HARDOON, D.; AYELE, S.; NIEVA, R. Uma economia para o 1\%: como privilégios e poderes exercidos sobre a economia geram situações desigualdade extrema e com esse quadro pode ser revertido. Documento Informativo 210 OXFAM, Oxford, 18 jan. 2016. Disponível em: <https://www.oxfam.org/sites/www.oxfam.org/files/file_attachments/bp210-economy-onepercent-tax-havens-180116-summ-pt.pdf>. Acesso em: 18 out. 2017.

MANDEL, E. O Capitalismo Tardio. São Paulo: Abril Cultural, 1982. (Os Economistas).

MARCONSIN, C. Cerco dos direitos trabalhistas e crise do movimento sindical. 2009. Tese (Doutorado em Serviço Social)-Escola de Serviço Social, Universidade Federal do Rio de Janeiro, Rio de Janeiro, 2009.

MARX, K.; ENGELS, F. Manifiesto del Comunista. Traducción al español. Moscu: Editorial Progreso, 1981.

NETTO, J. P. Crise do socialismo e ofensiva Neoliberal. 3 ed. São Paulo: Cortez, 2001. (Coleção Questões de Nossa Época).

OLIVEIRA, J. Dono do helicóptero que vitimou filho de Alckmin é próximo a PSDB e PT. Jornal Valor Econômico, São Paulo, 3 abr. 2015. Disponível em: <http://www.valor.com.br/politica/3991158/dono-do-helicoptero-que-vitimou-filho-dealckmin-e-proximo-psdb-e-pt>. Acesso em: 28 mar. 2018.

PAIM, J. Reforma Sanitária Brasileira: contribuição para a compreensão e crítica. Salvador: EDUFBA; Rio de Janeiro: Fiocruz, 2008.

SINDICATO NACIONAL DOS DOCENTES DAS INSTITUIÇÕES DE ENSINO SUPERIOR. Informandes, Brasília (DF), n. 67, fev. 2017. 
SOUSA, J. A elite do atraso: da escravidão à Lava-Jato. Rio de Janeiro: Leya Casa da Palavra, 2017.

TEIXEIRA, M. J. O. A Política Nacional de Saúde na contemporaneidade: as Fundações Estatais de Direito Privado na Saúde como direcionamento do fundo público. 2010. (Tese de Doutorado em Serviço Social)-Faculdade de Serviço Social, Universidade Estadual do Rio de Janeiro, Rio de Janeiro, 2010a.

TEIXEIRA, M. J. O. A Fundação Estatal de Direito Privado na Saúde e os impactos sobre os retrocessos sobre os Direitos dos trabalhadores do setor. In: MARCONSIN C.; MARQUES M. C. (Orgs.); FORTE, V.; GUERRA, Y. (Coords.). Trabalho e direitos: conquistas e retrocessos em debate. Rio de Janeiro: Lumen Juris, 2010b. p. 105-118.

TEIXEIRA, M. J. O. As Unidades de Pronto-Atendimento Pré-Hospitalar Fixo (UPAS) 24 hs. O fetiche do novo modelo de gestão. Política de Saúde Hoje: Interfaces \& Desafios no trabalho dos Assistentes Sociais. Campinas: Papel Social, 2014. p. 45-66.

\section{Mary Jane de Oliveira TEIXEIRA}

Assistente Social. Mestre em Saúde Pública, pela ENSP/FIOCRUZ/MS. Doutora em Serviço Social pela UERJ. Professora-Adjunta da Faculdade de Serviço Social da UERJ. Coordenadora do Grupo de Pesquisa inscrito no diretório do CNPq e Projeto de Extensão /UERJ, do Observatório do Trabalho no Brasil. 